\title{
Multivariate Estimation of Rock Mass Characteristics Respect to Depth Using ANFIS Based Subtractive Clustering- Khorramabad - Polezal Freeway Tunnels
}

\author{
*Moosavi S.H.; Engineer of Geo-Techniques and \\ Excavation Devision, Imensazan Engineering Consulting \\ Co, Water Conveyor Tunnel of Nosud Project, \\ Sharifzadeh M.; Faculty of Mining Eng, Mining and \\ Metallurgy, Amirkabir University of Technology
} Received: 26 Aug 2013 Revised: 30 Dec 2014

\begin{abstract}
Combination of Adoptive Network based Fuzzy Inference System (ANFIS) and subtractive clustering (SC) has been used for estimation of deformation modulus $\left(\mathrm{E}_{\mathrm{m}}\right)$ and rock mass strength $\left(\mathrm{UCS}_{\mathrm{m}}\right)$ considering depth of measurement. To do this, learning of the ANFIS based subtractive clustering (ANFISBSC) was performed firstly on 125 measurements of 9 variables such as rock mass strength $\left(\mathrm{UCS}_{\mathrm{m}}\right)$, deformation modulus $\left(\mathrm{E}_{\mathrm{m}}\right)$, depth, spacing, persistence, aperture, intact rock strength $\left(\mathrm{UCS}_{\mathrm{i}}\right)$, geomechanical rating (RMR) and elastic modulus $\left(\mathrm{E}_{\mathrm{i}}\right)$. Then, at second phase, testing the trained ANFISBSC structure has been perfomed on 40 data measurements. Therefore, predictive rock mass models have been developed for 2-6 variables
\end{abstract}

*Corresponding author sehamoosavi@gmail.com 
where model complexity influences the estimation accuracy. Results of multivariate simulation of rock mass for estimating $\mathrm{UCS}_{\mathrm{m}}$ and $\mathrm{E}_{\mathrm{m}}$ have shown that accuracy of the ANFISBSC method increases coincident with development of model from 2 variables to 6 variables. According to the results, 3-variable model of ANFISBSC method has general estimation of both $\mathrm{UCS}_{\mathrm{m}}$ and $\mathrm{E}_{\mathrm{m}}$ corresponding with $20 \%$ to $30 \%$ error while the results of multivariate analysis are successfully improved by 6-variable model with error of less than 3\%. Also, dip of the fitted line on data point of measured and estimated $\mathrm{UCS}_{\mathrm{m}}$ and $\mathrm{E}_{\mathrm{m}}$ for 6-variable model approaches about 1 respect to 0.94 for 3-variable model. Therefore, it can be concluded that 6-variable model of ANFISBSC gives reasonable prediction of $\mathrm{UCS}_{\mathrm{m}}$ and $\mathrm{E}_{\mathrm{m}}$.

Keywords: ANFIS, Subtractive clustering, Rock mass carachteristics, Deformation modulus, Rock mass compressive strength, Multivariate model, KhorramabadPolezal.

\section{Introduction}

Geotechnical survey and quantification of rock mass characteristics constitutes basic proportion of construction of underground openings. Therefore, recognition of project risks and parameters, which control the designation of tunnels, is important in geological studies [1]. These studies start before tunnel construction and respect to tunneling stage, will expand in several phases by desk study, laboratory tests and field measurements. Final geotechnical surveys will continue even after the tunnel construction to modify or certify aforementioned predictions [12]. 
For a given Rock mass property, measurements have different values instead of the same data values; suppose, $\mathrm{X}$ is real value of special quantity and $\alpha$ is variability of the measurements; therefore, data measurements distribution (y) could be calculated as [3]:

$$
\mathrm{y}=\mathrm{X} \mp \alpha
$$

Equation 1 conceptually determines the uncertainty of real value (x). Utilization of models that are contained of more predictive carachteristics which simulate the rock mass could increase the precision of predictions coincident with the variability of measured data set. Variability of rock mass characteristics could be estimated by several methods in the concept of multivariate analysis. Regression analysis included by linear and nonlinear methods constitutes procedure, which has been used in different branches of science, especially for estimation of uncertainty of rock mass model. However, for the sake of imperfection of estimation and imprecision results respect to measured data, researchers are decided to find other methods to substitute the regression methods that are capable to map the designation of input data set on the output data for nonlinear behavior of data. Therefore, combination of adoptive network based fuzzy inference system (ANFIS) and subtractive clustering (SC) has utilized for estimation of $\mathrm{UCS}_{\mathrm{m}}$ and $\mathrm{E}_{\mathrm{m}}$. This code possesses both neuro-fuzzy and subtractive clustering preferences [4]. 


\section{Geology and engineering geology of Khorramabad- Polezal freeway}

Khorramabad-polezal freeway in the southwest of Iran with the length of $105 \mathrm{~km}$ connects the khorramabad city to the polezal, is substituted to the tortuous, rising and falling old route with $165 \mathrm{~km}$ length (Figure 1). Khorramabad-Polezal freeway has the advantage of reduction in travel time from 2:30 $\mathrm{min}$ to 1 hour [5]. This project includes of 12 twin tunnels, which all have the horseshoe section [5]. Geological formations of the project region are Talezang $(\mathrm{Tz})$, Sarvak $(\mathrm{Ks})$, Asmari $(\mathrm{Om})$, Gurpi $(\mathrm{Gu})$ and Ilam $(\mathrm{Ku})$ having limestone, argillaceous limestone and shale rocks.

\section{Data survey}

Preconstruction site investigation has been performed on the outcrops and slopes. Also geotechnical surveys have been continued during the construction of tunnels in tunnel route (Figure 2). Joint characteristics have been studied through the use of scan line method and categurized by ISRM suggested methods and rating.

According to the geological surveys, Uni-axial compressive strength $\left(\mathrm{UCS}_{\mathrm{i}}\right)$ and elastic modulus of rocks are determined by the using schmith hammer tests; therefore, following empirical equations are employed to transform schmith hammer rebound number to the intact rock strength and elastic modulus [6]:

$$
\begin{array}{ll}
\sigma_{\mathrm{c}}=12.74 \mathrm{e}^{0.185 \rho \mathrm{R}_{\mathrm{n}(\mathrm{L})}} & \text { Beverly, } 1979 \\
\sigma_{\mathrm{c}}=6.9 * 10^{\left[0.0087 \rho \mathrm{R}_{\mathrm{n}(\mathrm{L})+} 0.16\right]} & \text { Deer\& Miller, } 1966
\end{array}
$$




$$
\begin{array}{ll}
E=0.6005 \rho R_{n(L)}-2.0276, & \text { Deer \& Miller, } 1966 \\
E=0.192 \rho^{2} R_{n(L)}-12.71, & \text { Beverly, } 1979
\end{array}
$$

Also, Deformation modulus and rock mass strength are calculated by average of several empirical relations with the given RMR and GSI (Table 1). So, collected data have been categurized to traning and testing data sets. According to depth dependent variability of rock mass characteristics [7] trining data set of 125 measurements of 9 properties of rock mass consist of depth, spacing, persistence, aperture, $\mathrm{UCS}_{\mathrm{i}}, \mathrm{E}_{\mathrm{i}}, \mathrm{E}_{\mathrm{m}}, \mathrm{UCS}_{\mathrm{m}}$ and rock mass rating (RMR), constitute the space of 2 to 6 variable models of rock mass to map the structure of $\mathrm{UCS}_{\mathrm{m}}$ and $\mathrm{E}_{\mathrm{m}}$ by ANFISBSC. Then, testing data set of 40 measurements has been utilized to calculate the predictibility of trained structure for estimation of $\mathrm{UCS}_{\mathrm{m}}$ and $\mathrm{E}_{\mathrm{m}}$.

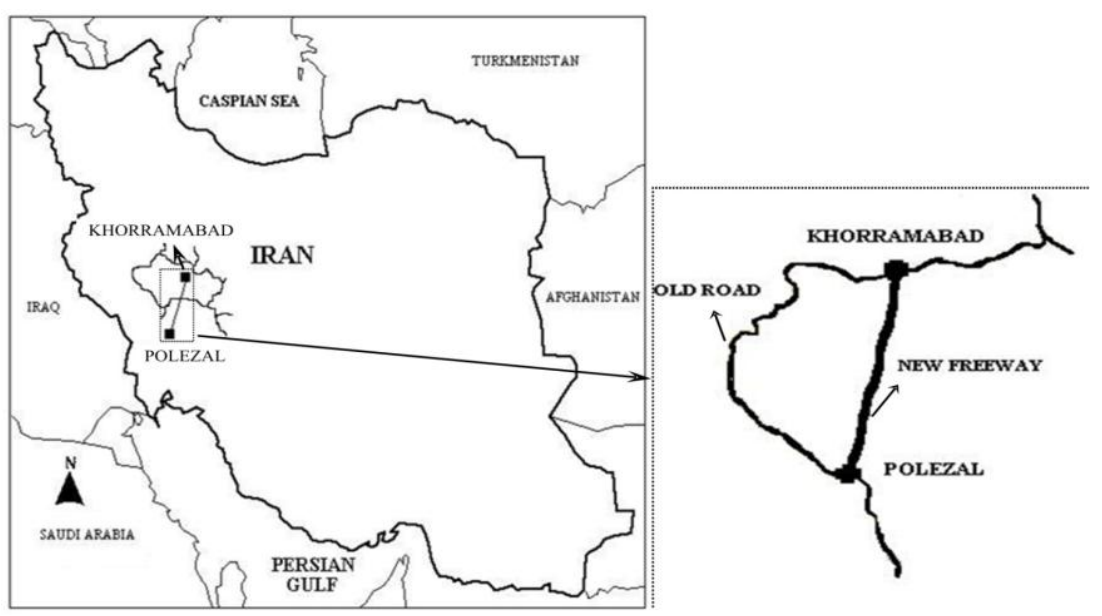

Figure1. Geographical position of Khorramabad-Polezal freeway [8] 

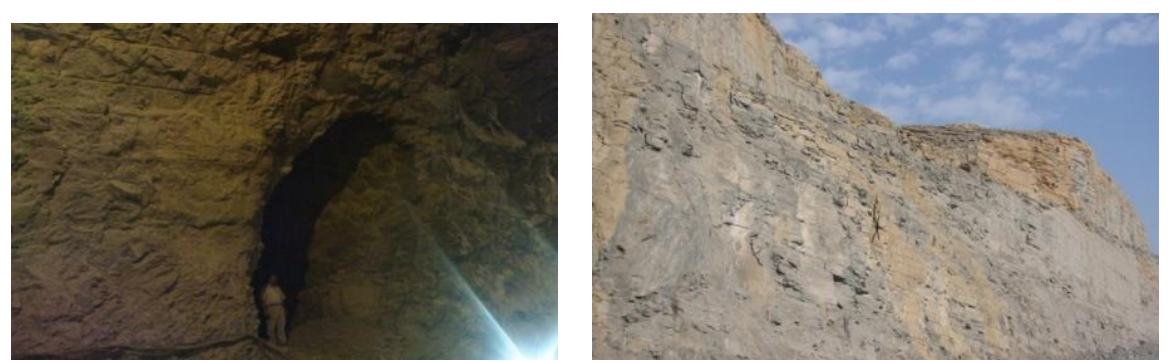

Figure2. Geological survey at preconstruction stage on autcrops and slopes (right) at construction stage in tunnel route (left) [8] Table1. Empirical equations to calculate UCSm and Em [8]

\begin{tabular}{|c|c|c|c|}
\hline $\begin{array}{c}\text { Rock mass strength } \\
\text { (MPa) }\end{array}$ & Proposed by & $\begin{array}{l}\text { Deformation modulus } \\
\text { (GPa) }\end{array}$ & Proposed by \\
\hline$\frac{\sigma_{\mathrm{cm}}}{\sigma_{\mathrm{c}}}=\mathrm{e}^{\frac{7.65(\mathrm{RMR}-100)}{100}}$ & Yudhbir, 1983 & $\mathrm{E}_{\mathrm{m}}=\mathrm{E}(0.0231 \mathrm{RQD}-1.32)$ & Gardner, 1987 \\
\hline$\frac{\sigma_{\mathrm{cm}}}{\sigma_{\mathrm{c}}}=\mathrm{e}^{\frac{\mathrm{RMR}-100}{18.75}}$ & $\begin{array}{l}\text { Ramamurthy, 1985-6, } \\
1993\end{array}$ & $\begin{array}{l}\mathrm{E}_{\mathrm{m}}= \\
\frac{\mathrm{E}\left[0.0028 \mathrm{RMR}^{2}+0.9 \exp \left(\frac{\mathrm{RMR}}{22.82}\right)\right]}{100}\end{array}$ & $\begin{array}{l}\text { Bieniawski, } \\
1990\end{array}$ \\
\hline$\sigma_{\mathrm{cm}}=0.5 \mathrm{e}^{0.06 \mathrm{RMR}}$ & $\begin{array}{l}\text { Trueman, } 1988 \& \\
\text { Asef,2000 }\end{array}$ & $\begin{array}{l}\mathrm{E}_{\mathrm{m}}=300 \exp (0.07 \mathrm{RMR}) * \\
10^{-3}\end{array}$ & Kim, 1993 \\
\hline$\frac{\sigma_{\mathrm{cm}}}{\sigma_{\mathrm{c}}}=\mathrm{e}^{\frac{\mathrm{RMR}-100}{24}}$ & Bieniawski, 1993 & $\mathrm{E}_{\mathrm{m}}=\frac{\mathrm{E}}{2}\left[1-\cos \left(\pi * \frac{\mathrm{RMR}}{100}\right)\right]$ & Mitri, 1994 \\
\hline$\frac{\sigma_{\mathrm{cm}}}{\sigma_{\mathrm{c}}}=\mathrm{e}^{\frac{\mathrm{GSI}-100}{18}}$ & Hoek, 1994-5 & $\mathrm{E}_{\mathrm{m}}=0.0736 \mathrm{e}^{0.0755 \mathrm{RMR}}$ & Gokceoglu, \\
\hline$\frac{\sigma_{\mathrm{cm}}}{\sigma_{\mathrm{c}}}=\mathrm{e}^{\frac{\mathrm{RMR}-100}{20}}$ & Sheorey, 1997 & $\mathrm{E}_{\mathrm{m}}=0.1451 \mathrm{e}^{0.0654 \mathrm{GSI}}$ & 2003 \\
\hline$\frac{\sigma_{\mathrm{cm}}}{\sigma_{\mathrm{c}}}=\frac{\mathrm{RMR}}{\mathrm{RMR}+6(100-\mathrm{RMR})}$ & Aydan, 1998 & $\mathrm{E}_{\mathrm{m}}=0.33 \mathrm{e}^{0.064 \mathrm{GSI}}$ & Hoek, 2004 \\
\hline \multirow{4}{*}{$\frac{\sigma_{\mathrm{cm}}}{\sigma_{\mathrm{c}}}=0.036 \mathrm{e}^{\frac{\mathrm{GSI}}{30}}$} & \multirow{4}{*}{ Hoek, 2004} & $\begin{array}{l}E_{\mathrm{m}}= \\
\mathrm{E} * 10\left[\left(\frac{(\mathrm{RMR}-100)(100-\mathrm{RMR})}{4000 \exp \left(-\frac{\mathrm{RMR}}{100}\right)}\right)\right]\end{array}$ & Sonmez, 2006 \\
\hline & & $\mathrm{E}_{\mathrm{m}}=\mathrm{E} * 10^{0.0186 \mathrm{RQD}-1.91}$ & \multirow{3}{*}{ Zhang, 2004} \\
\hline & & $\mathrm{E}_{\mathrm{m}}=1.8 \mathrm{E} * 10^{0.0186 \mathrm{RQD}-1.91}$ & \\
\hline & & $\mathrm{E}_{\mathrm{m}}=0.2 \mathrm{E} * 10^{0.0186 \mathrm{RQD}-1.91}$ & \\
\hline
\end{tabular}




\section{Estimation of $\mathrm{UCS}_{\mathrm{m}}$ and $\mathrm{E}_{\mathrm{m}}$ with ANFISBSC}

Considering the importance of rock mass strength and deformation modulus for design of tunnels in the cases of stability analysis, numerical modeling and excavation cycle process, ANFISBSC has been applied to model rock mass by 2 to 6 variables for having accurate estimation of $\mathrm{UCS}_{\mathrm{m}}$ and $\mathrm{E}_{\mathrm{m}}$. in order to this, multivariate model of rock mass is developed according to table 2. Therefore, consequent structure of training stage is used to test the generalization of multivariate model on 40 measurements of testing data set.

Table 2. Development of predictive model of rock mass for estimation of $\mathrm{UCS}_{\mathrm{m}}$ and $\mathrm{E}_{\mathrm{m}}$

\begin{tabular}{|c|c|c|c|c|c|c|c|}
\hline \multirow{2}{*}{$\begin{array}{c}\text { Multivariate } \\
\text { Model }\end{array}$} & $\begin{array}{c}\text { Estimated Rock Mass } \\
\text { Property }\end{array}$ & \multicolumn{6}{|c|}{ Rock mass modeling Properties for Multivariate } \\
\hline & $\begin{array}{c}\text { De } \\
(\mathrm{m})\end{array}$ & $\begin{array}{c}\mathrm{Sp} \\
(\mathrm{cm})\end{array}$ & $\mathrm{Pe}(\mathrm{m})$ & $\begin{array}{c}\mathrm{Ap} \\
(\mathrm{mm})\end{array}$ & $\begin{array}{c}\mathrm{UCS}_{\mathrm{i}} \\
(\mathrm{MPa})\end{array}$ & $\begin{array}{c}\mathrm{E}_{\mathrm{i}} \\
(\mathrm{GPa})\end{array}$ \\
\hline \multirow{2}{*}{ 2-Variable } & $\mathrm{UCS}_{\mathrm{m}}$ & & & & & & \\
\hline & $\mathrm{E}_{\mathrm{m}}$ & & & & & & \\
\hline \multirow{2}{*}{ 3-Variable } & $\mathrm{UCS}_{\mathrm{m}}$ & & & & & & \\
\hline & $\mathrm{E}_{\mathrm{m}}$ & & & & & & \\
\hline \multirow{2}{*}{ 4-Variable } & $\mathrm{UCS}_{\mathrm{m}}$ & & & & & & \\
\hline & $\mathrm{E}_{\mathrm{m}}$ & & & & & & \\
\hline \multirow{2}{*}{ 6-Variable } & $\mathrm{UCS}_{\mathrm{m}}$ & & & & & & \\
\cline { 2 - 8 } & $\mathrm{E}_{\mathrm{m}}$ & & & & & & \\
\hline
\end{tabular}

estimation of $\mathrm{UCS}_{\mathrm{m}}$ and $\mathrm{E}_{\mathrm{m}}$ by 2, 4 and 6-variable models of ANFISBSC method at training data set have been compared schematicaly with the measured data in Figure 3. According to this Figure, training result of ANFISBSC has been shown in points where the main data are represented by line. As depicted, estimation of 2variable model simulated by ANFISBSC is included with the most 
deviation respect to main data of $\mathrm{E}_{\mathrm{m}}$ and $\mathrm{UCS}_{\mathrm{m}}$; which the accuracy of the estimation is improved at 4-variable model; But with scrutiny on the result of 6-variable model, it is clear that ANFISBSC method successfully has been estimated the $\mathrm{E}_{\mathrm{m}}$ and $\mathrm{UCS}_{\mathrm{m}}$ data. The consequent structure of trained ANFISBSC is tested on the space of 40 observations of testing data set. Figure 4 demonstrates the results of 2, 4 and 6variable modeling of ANFISBSC on testing data set. Comparison of ANFISBSC estimation and main data at testing data set (Figure 4) verifies similar results of giving Figure 3; this finding implies on the unique flexibility of ANFISBSC method for mapping input parameters to the output parameter with the optimized fuzzy rules and membership functions. Also, 6-variable model has the best estimation of $E_{m}$ and $\mathrm{UCS}_{\mathrm{m}}$ compared with main data of $\mathrm{E}_{\mathrm{m}}$ and $\mathrm{UCS}_{\mathrm{m}}$. So, to quantify demonstrated results of Figure $3 \& 4,3$ and 6-variable models have been chosen. The comparison of trained 3 and 6 -variable models estimating $\mathrm{E}_{\mathrm{m}}$ demonstrated in Figure 5; also, Figure 6 shows the accuracy of ANFISBSC result for assessing $\mathrm{UCS}_{\mathrm{m}}$ at 3 and 6 variable models. Figure 5 (or Figure 6) includes two sub-Figureure which at first sub-Figureure, vertical and horizontal axis is ranged by ANFISBSC result and main data of $\mathrm{E}_{\mathrm{m}}$ (or $\mathrm{UCS}_{\mathrm{m}}$ ) respectively; therefore fitted line on data points shows the accuracy of the estimation. Also at second sub-Figureure, the difference of two values of ANFISBSC and main data of $\mathrm{E}_{\mathrm{m}}$ (or $\mathrm{UCS}_{\mathrm{m}}$ ) representes vertical axis named "residual"; and main data of $\mathrm{E}_{\mathrm{m}}$ (or $\mathrm{UCS}_{\mathrm{m}}$ ) is shown on horizontal axis. As shown in 
Figure 5 and 6, 3-variable model of ANFISBSC method has general estimation of both $\mathrm{UCS}_{\mathrm{m}}$ and $\mathrm{E}_{\mathrm{m}}$ corresponding with $20 \%$ to $30 \%$ error; while the results of multivariate analysis are successfully improved by 6-variable model with error of less than $3 \%$. Also more proximity of the fitted line dip to 1 implies on more accuracy of the estimation. As shown, dip of the fitted line for 6-variable model approaches about 1 compared to dip of 0.94 for 3-variable model. Therefore it has been concluded that 6-variable model of ANFISBSC gives reasonable estimation of $\mathrm{UCS}_{\mathrm{m}}$ and $\mathrm{E}_{\mathrm{m}}$ having the trained structure on measured data.

\section{Discussion}

Determination of rock mass characteristics is one of the important stages of designing the structures built on, in or of rock. At elementary steps of the projects with shortages of finance and economics and accessibility for data survey or running in-situ tests, results of last projects data acquisition and leaded empirical relations include one of the best methods to estimate the rock mass data related to our project sites for designing the tunnels, dams, caverns and the other rock structures [8]. This idea is the main reason of different empirical relation existence which some of data survey leaded to make equation between rock mass characteristics. Regression analysis including linear and nonlinear for multivariate or single-variate models has been utilized to estimate the rock mass data according to dependent variable(s). But the results of regression analysis could be used for the 
same conditions of petrology, in-situ and induced stresses, underground hydrology and dimensions or type of the structures built in rock. So, equations achieved by regression analysis are case study based that means one relation for special study. Also, accuracy or precision of the resulted relations are dependent on the number of data and the functions mapping independent variable(s) to dependent variable [4]. There for imperfection of regression analysis lead to use neural network for more precise and accurate estimation of rock mass characteristics; neural network method are good to map principles between data sets that for more rapid reaching to the answer different codes have been issued. But for improving the convergence of the answer to local minimum, neural network codes are combined with Fuzzy inference systems. One of these codes is ANFIS witch contains both benefits of neural network and fuzzy inference systems; that fuzzy if- then rules are trained in the manner of Adoptive neural network. But also determination of fuzzy inference system in the form of if-then rules is time consuming job and needed to expert of both context of fuzzy inference system and special scientific data set. So, for easy determination of fuzzy if-then rules the ANFIS code has been merged to subtractive clustering code to make ANFIS Based Subtractive Clustering. In this code, fuzzy if-then rules are determined by subtractive clustering code for iterative training at ANFIS witch map the input data to output data in the way of training - testing running of code [4]. Therefore good approximation of rock mass data could be supplied with using ANFISBSC code based on geological data survey, laboratory or in-situ tests. ANFISBSC isn't case study 
base that the results can be extended toward the generalization all over the world coincident with training and testing the ANFISBSC code on new data [4].

\section{Conclusion}

ANFISBSC algorithm has been employed to estimate $\mathrm{UCS}_{\mathrm{m}}$ and $\mathrm{E}_{\mathrm{m}}$ at two categories of training and testing data sets coincident with development of 2-variable multivariate model to 6-variable model. As resulted, rock mass strength $\left(\mathrm{UCS}_{\mathrm{m}}\right)$ and deformation modulus $\left(\mathrm{E}_{\mathrm{m}}\right)$, have estimated successfully by 6-variable model of rock mass with error of less than $3 \%$. Although, estimation given by 3-variable model has included with $20-30 \%$ error comparing with measured data, but also trained structure lead to general estimation of rock mass characteristics. Therefore, ANFISBSC could be successfully utilized when computing complex models.

\section{Acknowledgement}

The authors are very grateful and wish to thanks the Iran Oston consulting company for their cooperation and providing data, facilities and supports. In addition, valuable comments by anonymous reviewers are sincerely appreciated. 

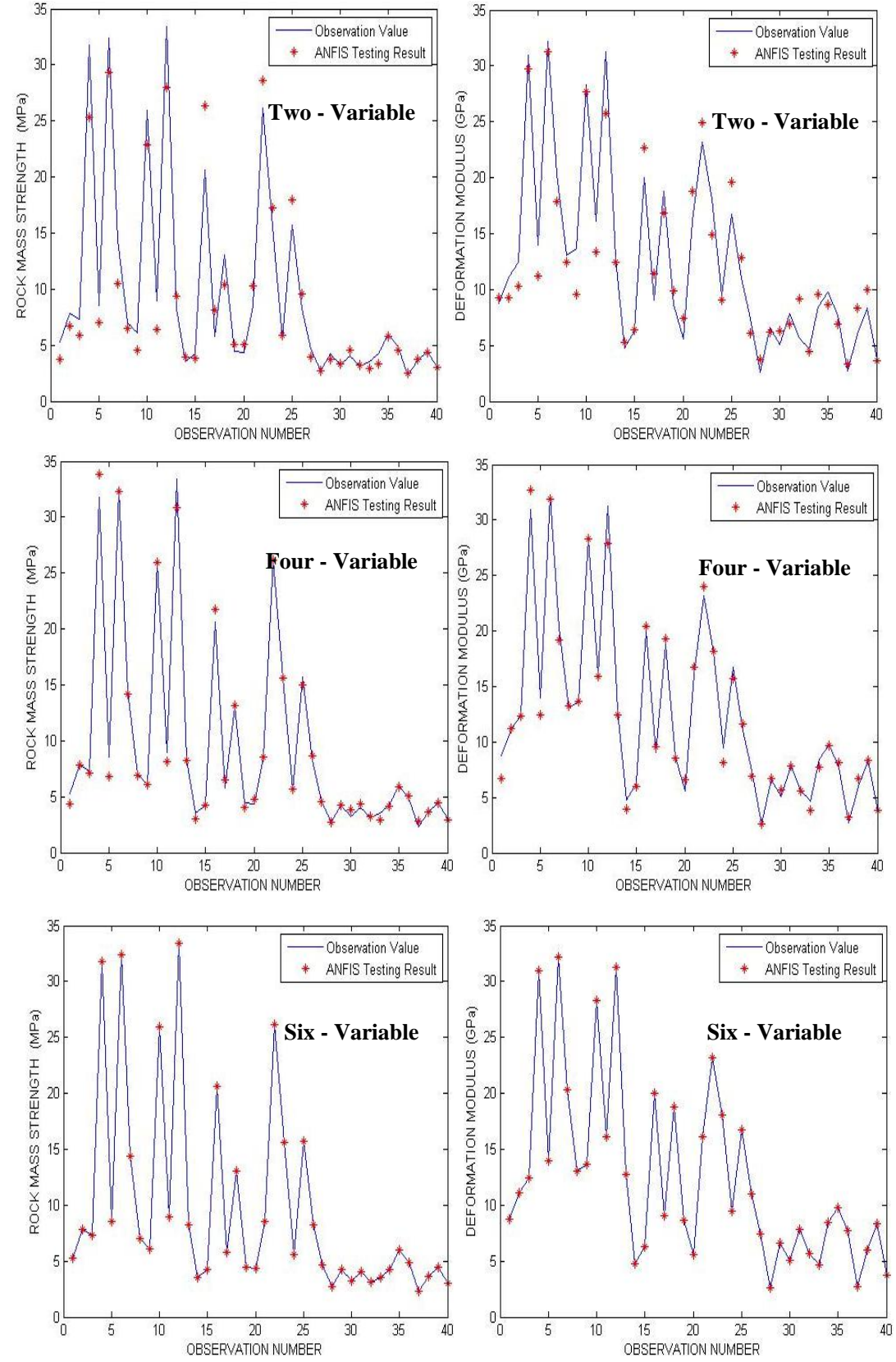

Figure 3. Schematic predictability estimation of the out-put structure of trained ANFISBSC: comparing $\mathbf{E}_{\mathrm{m}} \& \mathrm{UCS}_{\mathrm{m}}$ observation values (Tab.3) and modeled ones by ANFISBSC method for 2, 4 and 6-variable models 

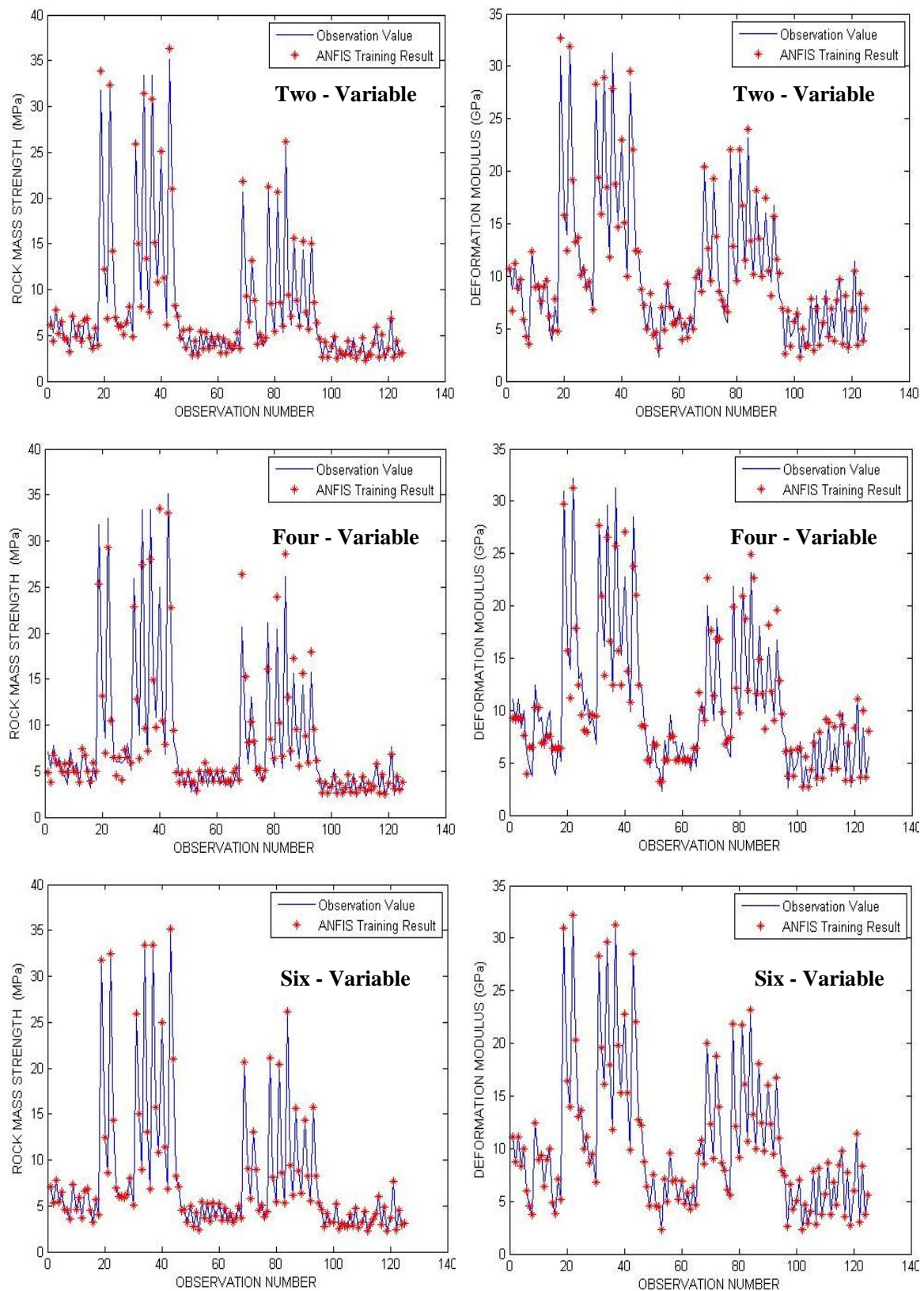

Figure 4. Schematic predictability estimation of the output structure of trained ANFISBSC for testing data set: comparing observation values (Tab.3) and simulated ones by ANFISBSC for 2, 4 and 6- variable models [8] 

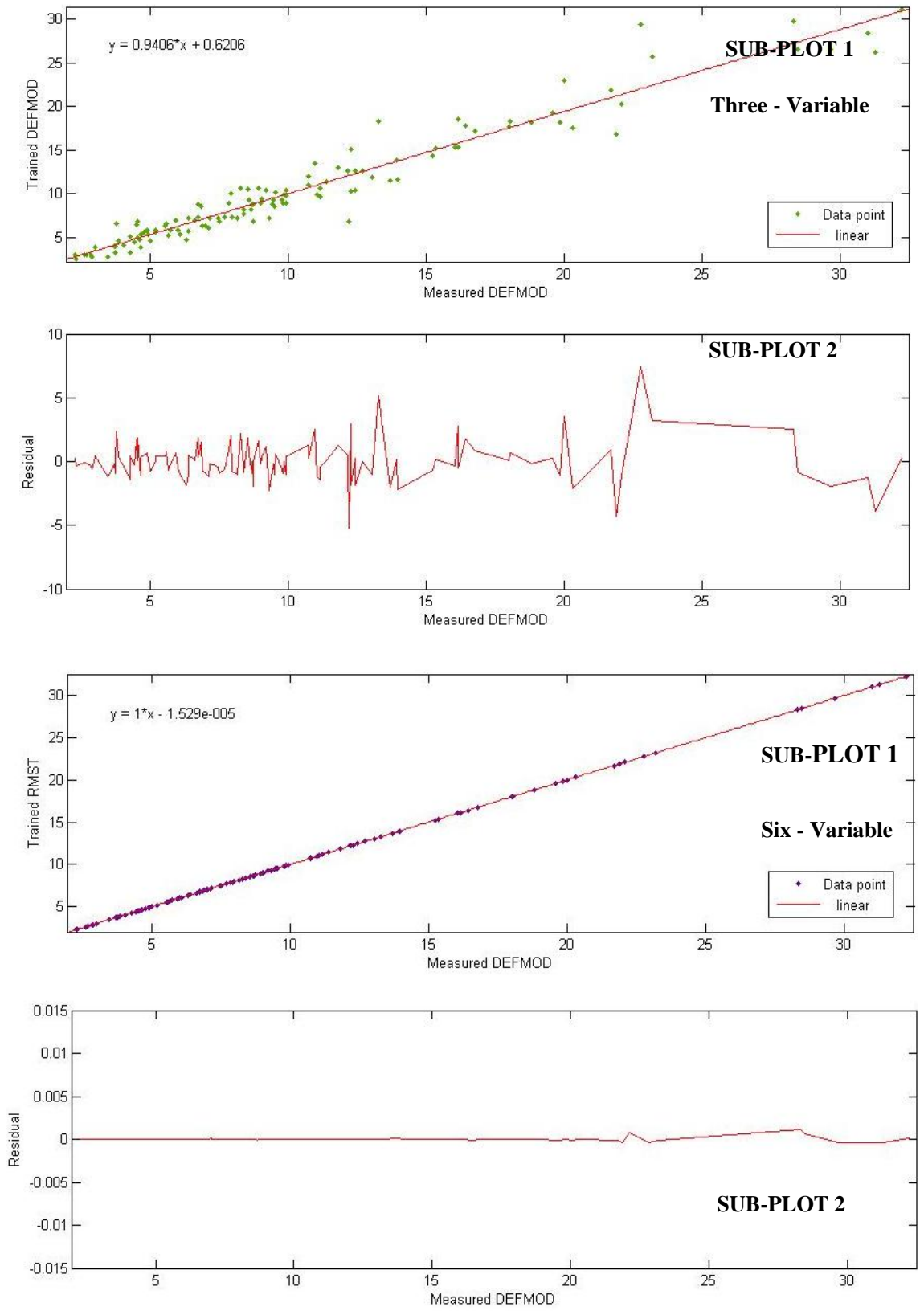

Figure 5. Analytically predictability estimation of the output structure of trained ANFISBSC comparing $\mathbf{E}_{\mathrm{m}}$ (DEFMOD) measurements (Tab.3) versus modeled ones by ANFISBSC method (sub-plot 1) and residual values (sub-plot 2) for 3 and 6- variable simulations [8]. 

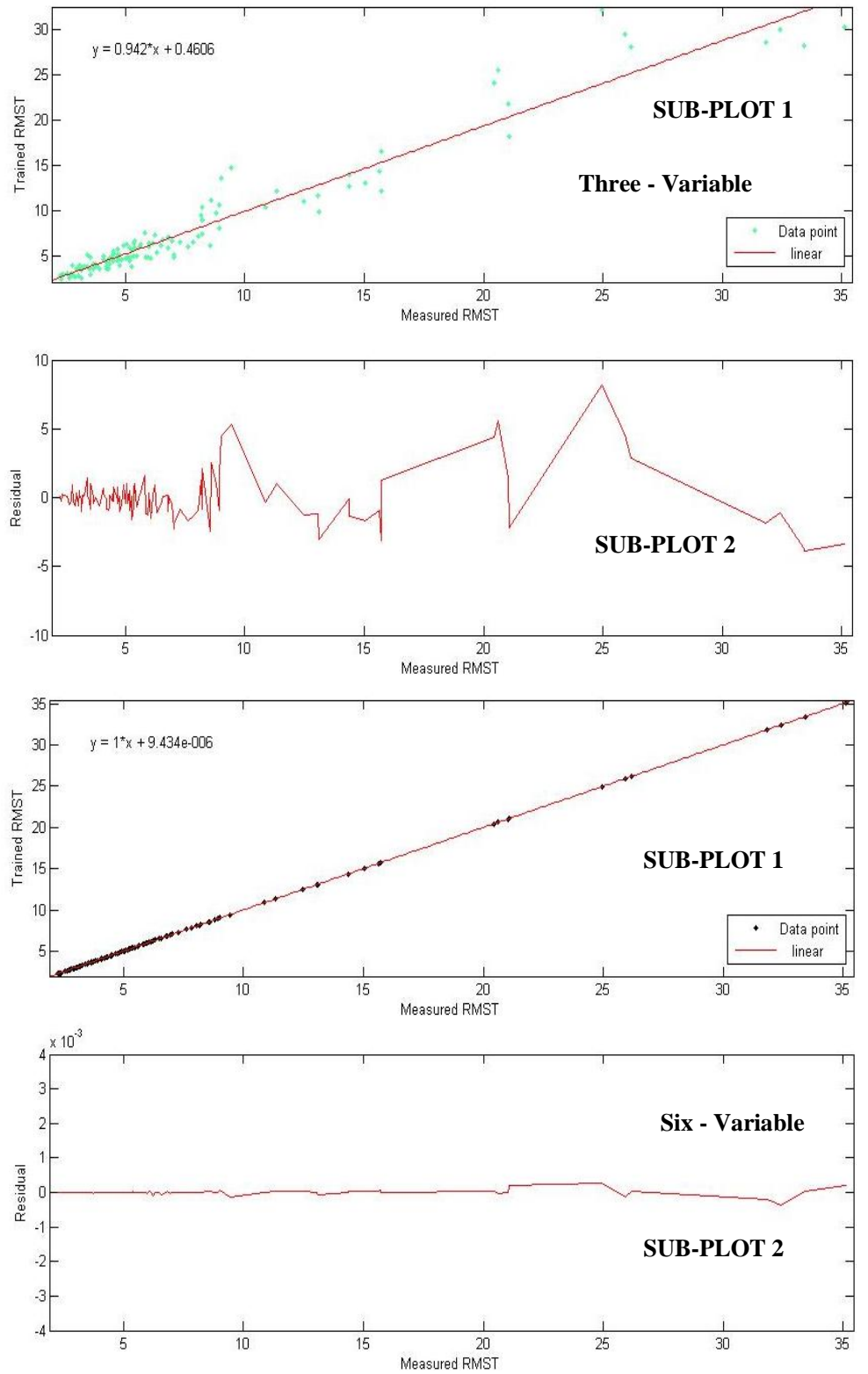

Figure 6. Analytically predictability estimation of the output structure of trained ANFISBSC comparing $\mathrm{UCS}_{\mathrm{m}}$ (RMST) measurements (Tab.3) versus modeled ones by ANFISBSC method (sub-plot 1) and residual values (sub-plot 2) for 3 and 6- variable simulations [8]. 


\section{References}

1. Shahriar K., Sharifzadeh M., Khademi J., "Geotechnical risk assessment based approach for rock TBM selection in difficult ground conditions", Tunnelling and Underground Space Technology, 23 (2008) 318-325.

2. Sharma V. M., Saxena K.R., "In-situ characterization of rocks", Taylor and Francis groups (2002).

3. Baecher G. B., Christian J. T., "Reliability and statistics in geotechnical engineering". USA: John Wiley \& Sons (2003).

4. Chiu, S., "Fuzzy model identification based on cluster estimation". J. Intell, Fuzzy Syst, v. 2 (1994) 267-278.

5. Iran Oston Consulting Eng., "Geology and geotechnical reports on Khorramabad-Polezal freeway" (2007).

6. Zhang L., "Engineering properties of rocks", Elsevier geo-engineering book series, v. 4 (2005).

7. Moosavi S. H., Sharifezadeh M., "General Idea for Study of Rock Mass Variability Respect to Depth (Freeway Tunnels of Khorramabad-Polezal)", Journal of Engineering Geology, Vol. 3. No.1\&2 (2010) 51-70.

8. Moosavi S. H., "Comparison of engineering rock mass properties at investigation stage to actual measured data at construction stage -applied in Khorram abad-Polezal tunnels", MSc Thesis, Amirkabir University of Technology (Tehran Polytechnic), Iran (2010). 